\title{
RADIOCARBON DATING OF THE HUMAN OCCUPATION OF AUSTRALIA PRIOR TO 40 ka BP-SUCCESSES AND PITFALLS
}

\author{
L K Fifield ${ }^{1,2} \bullet$ M I Bird ${ }^{3} \bullet$ C S M Turney ${ }^{3,4} \bullet$ P A Hausladen ${ }^{1} \bullet$ G M Santos ${ }^{1,5} \bullet$ M L di Tada ${ }^{1}$
}

\begin{abstract}
Charcoal samples from ancient human occupation sites in Australia have been subjected to a rigorous pretreatment and stepped combustion regime in order to explore the possibility that these sites may be older than previous radiocarbon dating had suggested. In one case, the Devil's Lair site in southwest Australia, the methodology has clearly removed vestiges of contamination by more modern carbon and has led to a revised radiocarbon chronology that provides evidence for human occupation of southwest Australia by at least $44 \mathrm{ka} \mathrm{BP}$ and probably by 46-47 ka BP. In contrast, charcoal from the Nauwalabila site has been so severely altered that insufficient of the original carbon remains for reliable ${ }^{14} \mathrm{C}$ dating. Finally, where the charcoal is well preserved, such as at the Carpenter's Gap site, the new results provide reassurance that earlier ${ }^{14} \mathrm{C}$ results of $\sim 40 \mathrm{ka} \mathrm{BP}$ are indeed true ages and are not simply at the limit of the ${ }^{14} \mathrm{C}$ technique.
\end{abstract}

\section{INTRODUCTION}

The upper limit to radiocarbon ages of the human occupation of Australia has been stubbornly stuck at $\sim 40 \mathrm{ka}$ for many years. This has led some authors to assert that humans arrived in Australia at this time (Allen and Holdaway 1995; O'Connell and Allen 1998). Recent evidence from other techniques, most notably thermoluminescence (TL) and optically stimulated luminescence (OSL), points however, to a more ancient arrival (Roberts et al. 1990, 1994). Is the $40 \mathrm{ka}$ limit real, in which case the luminescence dating is suspect? Or is the luminescence dating correct, and 40 ka represents a "radiocarbon barrier" imposed by the inability to remove traces of younger carbon from samples at the level of $<1 \%$ modern carbon?

In order to address this important question of the antiquity of human occupation of the Australian continent, a rigorous pretreatment and combustion methodology (acid-base-wet oxidation followed by stepped combustion-ABOX-SC) has been developed at the Australian National University (ANU) to remove as much as possible of non-original carbon from ancient charcoal (Bird et al. 1999). The application of this technique to three "case studies" of important sites in Australian archaeology is presented here.

\section{METHODS}

Details of the ABOX-SC technique are given by Bird et al. (1999). Briefly, charcoal that has been hand-picked from a particular archaeological level, or concentrated by sieving and flotation is subjected to the following pretreatment:

1. Treat with $6 \mathrm{M} \mathrm{HCl}$

2. Treat with $1 \mathrm{M} \mathrm{NaOH}$

3. Treat with $\mathrm{H}_{2} \mathrm{SO}_{4} / \mathrm{K}_{2} \mathrm{Cr}_{2} \mathrm{O}_{7}(0.1 \mathrm{M} / 2 \mathrm{M})$ solution at $60{ }^{\circ} \mathrm{C}$ for up to $14 \mathrm{hr}$.

The material that remains after this treatment is then placed in a silica tube with $\mathrm{CuO}$ and silver wire, and subjected to a three-stage combustion procedure. The first stage, at $340{ }^{\circ} \mathrm{C}$, is performed in the

\footnotetext{
${ }^{1}$ Department of Nuclear Physics, Research School of Physical Sciences and Engineering, Australian National University, Canberra, ACT 0200, Australia

${ }^{2}$ Corresponding author. Email: Keith.Fifield@anu.edu.au.

${ }^{3}$ Research School of Earth Sciences, Australian National University, Canberra, ACT 0200, Australia

${ }^{4}$ Centre for Quaternary Research, Royal Holloway, University of London, Egham, Surrey, TW20 0EX, United Kingdom

${ }^{5}$ Supported by a fellowship from CNPq, Brazil
}

(C) 2001 by the Arizona Board of Regents on behalf of the University of Arizona

Radiocarbon, Vol 43, Nr 2B, 2001, p 1139-1145

Proceedings of the 17th International ${ }^{14} \mathrm{C}$ Conference, edited by I Carmi and $\mathrm{E}$ Boaretto 
presence of $\mathrm{O}_{2}$ gas; the $\mathrm{CO}_{2}$ evolved during this step is usually discarded. The second and third steps are at 650 and $\sim 900{ }^{\circ} \mathrm{C}$, and utilize the oxygen from decomposition of the $\mathrm{CuO}$. Carbon dioxide from each of these two steps is collected and graphitized separately using catalytic reduction on iron at $650{ }^{\circ} \mathrm{C}$ in the presence of $\mathrm{H}_{2}$ gas.

The ${ }^{14} \mathrm{C} /{ }^{13} \mathrm{C}$ ratios of the samples were measured by accelerator mass spectrometry on the 14UD accelerator at the ANU. A fractionation correction was applied to the measured ratio assuming a value of $-25 \%$ o for the $\delta\left({ }^{13} \mathrm{C}\right)$ of the charcoal. Any uncertainty resulting from this assumption will be small compared to the statistical uncertainties on the results from these old samples.

\section{THE SITES AND RESULTS}

\section{The Devil's Lair Site: Human Occupation Dated by Radiocarbon to Pre-40 ka BP}

Devil's Lair is a limestone cave in the Margaret River region of West Australia. The name has been adopted by a nearby vineyard that makes excellent (and expensive) red wines. The stratigraphic sequence in the cave consists of $660 \mathrm{~cm}$ of sandy sediments intercalated with flowstone and bands of carbonate-cemented sediment. There is evidence for intermittent human occupation of the cave down to layer 30 at a depth of $\sim 350 \mathrm{~cm}$, with hearths, bone, and stone artifacts found throughout. Layer 30 represents a fan of topsoil that accumulated rapidly following widening of the cave mouth, and contains the earliest evidence for occupation of the cave itself. Below layer 30, in-situ artifacts are represented by only three stone flakes in level 34 and a single small flake in layer 37 . These were presumably washed into the cave with the sediments and indicate human activity in the surrounding area. The site has been described in detail by Dortch (1979a, 1979b). Earlier radiometric dating of the site using untreated or alkali-washed charcoal produced a coherent chronology down to $\sim 3 \mathrm{~m}$, but below $325 \mathrm{~cm}$ the ages were highly variable, and the oldest date was $38 \mathrm{ka}$ (Dortch and Dortch 1996). Accelerator mass spectrometry (AMS) dates on charcoal subjected to a more rigorous acidbase-acid pretreatment do not show the variability, but appear to reach a plateau at $\sim 40$ ka below $325 \mathrm{~cm}$ (Turney et al. 2000).

Charcoal from a series of depths in the sequence below $250 \mathrm{~cm}$ has been subjected to the ABOX-SC treatment. Results are superimposed on a diagram of the sedimentary sequence in Figure 1. Occupation of the cave is dated to around $44 \mathrm{ka} \mathrm{BP}$, and level 37, which contains the deepest artifact, is dated to around $45 \mathrm{ka}$ BP. Even older ages are obtained for the sterile layers below level 37, which indicates that the dates above this level are likely to be real ages, and are not simply reflecting the limit of the technique. A more detailed report of this work is forthcoming (Turney et al. 2000). For two of the samples, a variety of other common pretreatments were also undertaken in order to determine whether a simpler pretreatment than ABOX-SC might give equivalent results. Table 1 shows a comparison between the different pretreatments. Clearly, the full ABOX-SC treatment is required if reliable ages are to be obtained for the $>40 \mathrm{ka}$ BP samples from this site.

Calibration of the ${ }^{14} \mathrm{C}$ time scale in terms of calendar years is problematic in the time range beyond $40 \mathrm{ka}$. Simply taking into account the difference between the Libby half-life of 5568 years (used to calculate the ${ }^{14} \mathrm{C}$ age) and the presently accepted value of $5730 \mathrm{yr}$, however, increases a $45 \mathrm{ka}{ }^{14} \mathrm{C}$ age by 1300 yr. Recently, two calibrations that extend back beyond $40 \mathrm{ka}$ BP have been reported (Kitagawa and van der Plicht 1998; Voelker et al. 1998), and indicate offsets between sidereal and ${ }^{14} \mathrm{C}$ ages of $1-2 \mathrm{ka}$ at $45 \mathrm{ka} \mathrm{BP}$. Hence, the new ${ }^{14} \mathrm{C}$ results reported here imply the presence of people in the Devil's Lair area by $~ 46,000-47,000$ years ago. OSL, ESR and U-series ages are also available for this site (Turney et al. 2000), and the revised ${ }^{14} \mathrm{C}$ chronology from this work is in good agreement with them beyond $40 \mathrm{ka} \mathrm{BP}$. 


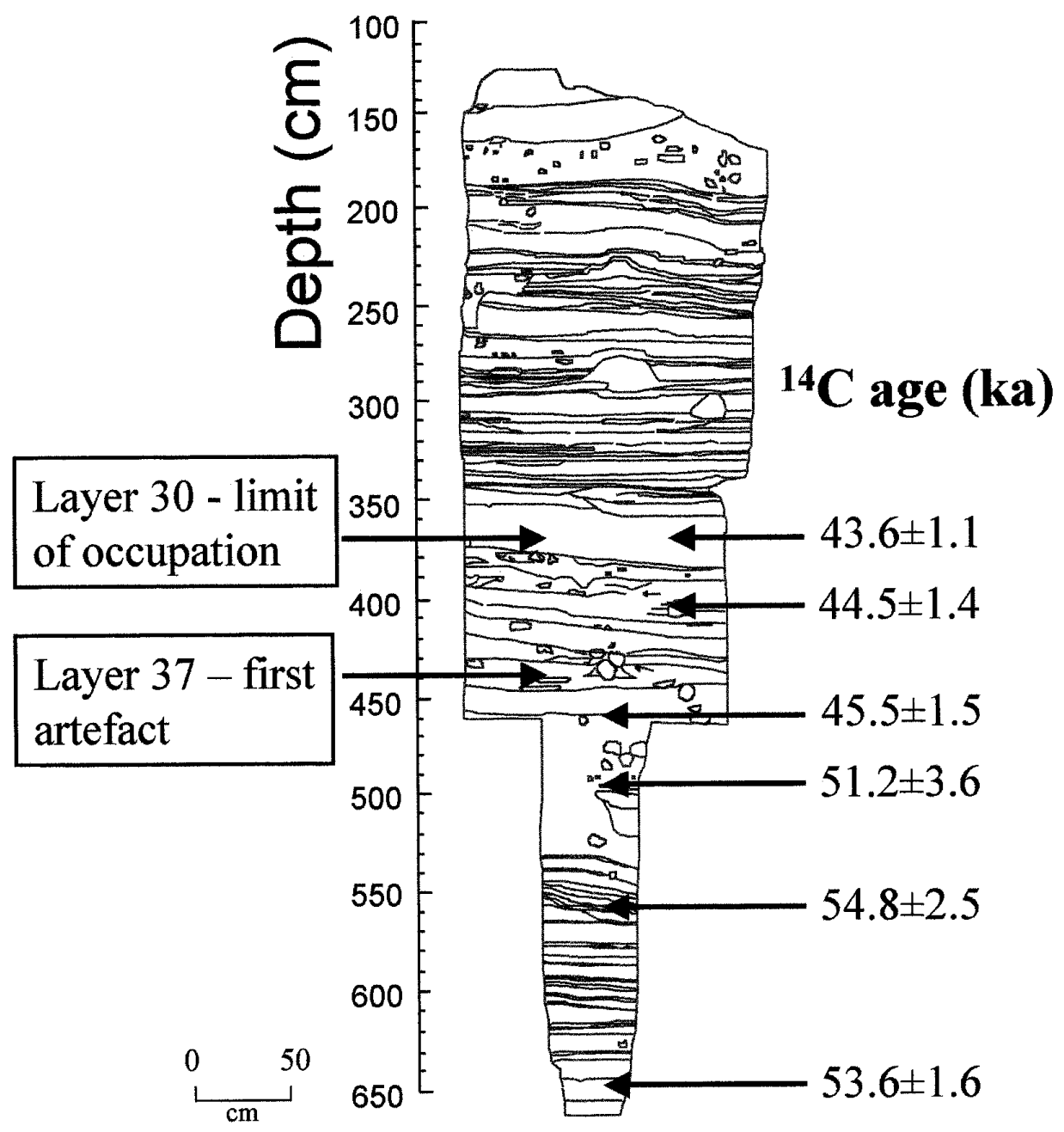

Figure 1 A schematic cross-section of the Devil's lair excavation showing the significant markers in the sequence and ABOX-SC-AMS radiocarbon ages

These results constitute the first definitive evidence from ${ }^{14} \mathrm{C}$ dating for the presence of humans in Australia before $40 \mathrm{ka} \mathrm{BP}$, and indicate that people had reached this extreme southwestern tip of the continent by at least $46-47 \mathrm{ka}$ ago. Crucial to this conclusion has been the combination of a stringent pre-treatment regime and a stepped combustion procedure. Between them, these seem to eliminate substantially more of the carbon incorporated into the samples during their period of burial than do more conventional pre-treatments followed by bulk combustion.

\section{The Nauwalabila Site: Failure of Radiocarbon Dating}

Nauwalabila is a rock overhang in the Kakadu National Park area of the Northern Territory. It comprises a 3-m-deep sequence of sands containing abundant evidence of human occupation. The site came to prominence following claims, based on thermoluminescence (TL) dating, that it had first been occupied at some time between 60 and $53 \mathrm{ka} \mathrm{BP}$. Previous ${ }^{14} \mathrm{C}$ dating of this site had, however, failed to yield ages older than $30 \mathrm{ka} \mathrm{BP}$, casting some doubt over the TL results. 
Table 1 Comparison of various pretreatments for samples from the Devil's Lair site

\begin{tabular}{cllll}
\hline Layer/depth $(\mathrm{cm})$ & Pretreatment & $\begin{array}{l}\text { Combustion } \\
\text { fraction }\left({ }^{\circ} \mathrm{C}\right)\end{array}$ & $\begin{array}{l}\text { Lab nr } \\
(\text { ANUA-) }\end{array}$ & $\begin{array}{l}\text { Radiocarbon } \\
\text { age }(k a \mathrm{BP})^{\mathrm{a}}\end{array}$ \\
\hline $30 / 365$ & HCl wash only & $880(\mathrm{i})^{\mathrm{b}}$ & 11506 & $42.0 \pm 1.6$ \\
$30 / 365$ & HCl wash only & $880(\mathrm{ii})^{\mathrm{b}}$ & 11505 & $41.1 \pm 1.9$ \\
$30 / 365$ & ABOX & 340 & 11504 & $41.4 \pm 1.2$ \\
$30 / 365$ & ABOX & 650 & 11503 & $42.6 \pm 1.9$ \\
$30 / 365$ & ABOX & 880 & 11502 & $43.6 \pm 1.0$ \\
$39 / 465$ & Base wash only & 340 & 10302 & $34.0 \pm 0.5$ \\
$39 / 465$ & Base wash only & 880 & 10303 & $40.0 \pm 0.8$ \\
$39 / 465$ & AOX & 880 & 10304 & $45.4 \pm 1.2$ \\
$39 / 465$ & ABOX & 340 & 10301 & $41.4 \pm 1.3$ \\
$39 / 465$ & ABOX & 880 & 11511 & $45.5 \pm 1.5$ \\
\hline
\end{tabular}

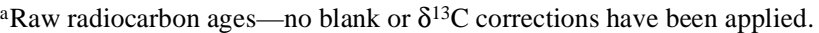

${ }^{\mathrm{b}} \mathrm{CO}_{2}$ evolved during first and second half of combustion at $880{ }^{\circ} \mathrm{C}$ was collected and graphitized separately.

In the present work, charcoal from the problematic depth range between 1.5 and $3 \mathrm{~m}$, and from different size fractions, has been subjected to the ABOX-SC treatment. Figure 2 summarizes the results from both this and earlier work. A more complete account of this work, including a catalogue of all of the data summarized in Figure 2, will be published elsewhere (Bird et al. forthcoming). Down to $\sim 1.3 \mathrm{~m}$, the ages from radiometric ${ }^{14} \mathrm{C}$ dating are in stratigraphic order and extend to $\sim 15 \mathrm{cal} \mathrm{ka}$. In addition, there is good agreement between the radiocarbon chronology and a TL date at $\sim 1.1 \mathrm{~m}$. Below $1.3 \mathrm{~m}$, however, the radiometric ${ }^{14} \mathrm{C}$ ages become highly variable. The TL dates, on the other hand, continue to increase monotonically with depth. It is clear from Figure 2 that the ABOX-SC treatment does nothing to reduce the variability in ${ }^{14} \mathrm{C}$ ages below $1.3 \mathrm{~m}$, nor does it produce any older dates than had been obtained previously by radiometric counting. Further, there is a lack of any clear correlation between age and size-fraction.

The onset of variability of the ${ }^{14} \mathrm{C}$ ages coincides with a dramatic fall in the amount of charcoal in the sequence, and the appearance of pisoliths. The latter are iron oxide nodules which are indicative of the presence of a fluctuating water table at some time in the past. It appears that, below $1.3 \mathrm{~m}$, much of the charcoal has disappeared. Further, what remains has been profoundly altered. Carbon contents of the charcoal were as low as $4 \%$ and iron and silica contents as measured by energy-dispersive X-ray analysis were high. The processes that led to this degradation were presumably also responsible for the disappearance of much of the charcoal from this part of the sequence. Several of the youngest ages cluster around 8-9 ka, and these may indicate the time at which the water table was high. A mechanism for degradation of the charcoal has not yet been identified, although microbial action is suspected. Further work is planned to elucidate these processes.

The conclusion in this case is that, below a depth of $1.3 \mathrm{~m}$, the ${ }^{14} \mathrm{C}$ ages are simply wrong. The moral is that there is some material that is so profoundly altered and contains so little of the original carbon that no amount of pretreatment can save it. Carbon analysis and electron microscopy of suspect material can save time spent on futile time-consuming pretreatments.

For this Nauwalabila site, therefore, the ${ }^{14} \mathrm{C}$ results are mute concerning the question of the antiquity of human occupation of the site. There thus appears to be no good reason to doubt the TL ages, and indeed, support for their validity is provided by the good agreement between ${ }^{14} \mathrm{C}$ and $\mathrm{TL}$ ages at $1.1 \mathrm{~m}$. They are also lent credence by the Devil's Lair results reported above which firmly establish human occupation of the Australian continent by $~ 46-47 \mathrm{ka}$ BP. 


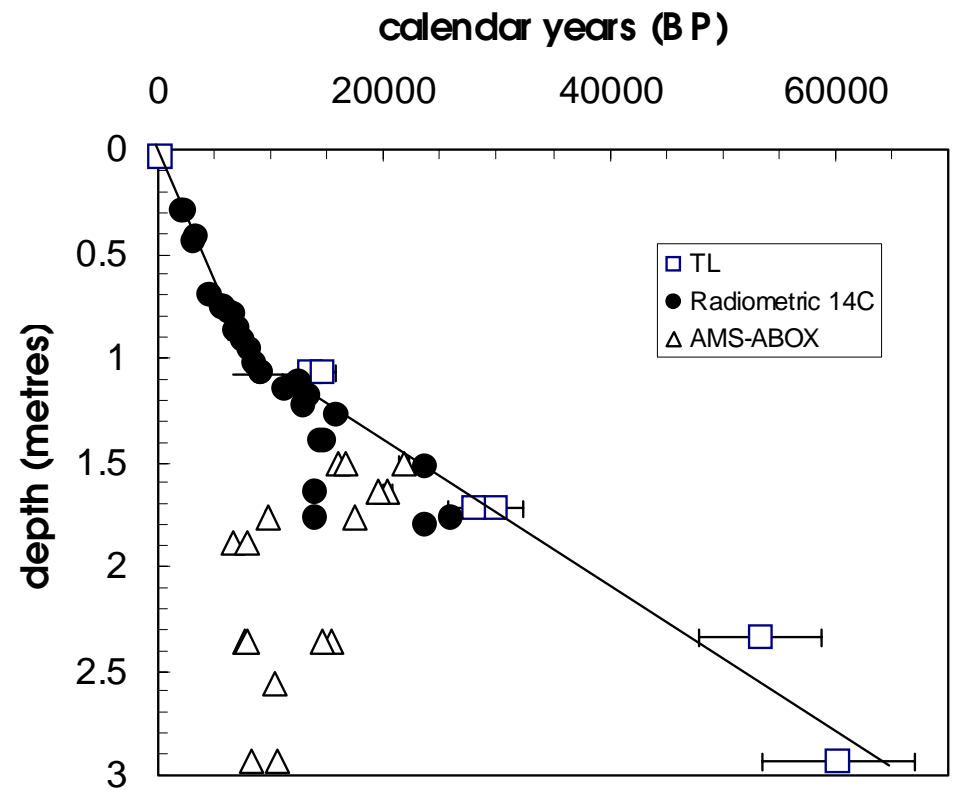

Figure 2 Comparison between radiometric ${ }^{14} \mathrm{C}$ dates, AMS ${ }^{14} \mathrm{C}$ dates on $\mathrm{ABOX}-\mathrm{SC}$ treated charcoal, and TL dates for the Nauwalabila site

Table 2 Results of radiocarbon measurements for ancient Australian archaeological sites

\begin{tabular}{|c|c|c|}
\hline Site and sample description & ANUA nr & $\begin{array}{l}\text { Radiocarbon age } \\
(\mathrm{ka} \mathrm{BP})^{\mathrm{a}}\end{array}$ \\
\hline \multicolumn{3}{|l|}{ Carpenter's Gap } \\
\hline CG1-A 45, $90 \mathrm{~cm}$, ABOX $880^{b}$ & 8130 & $33.2 \pm 0.6$ \\
\hline CG1-A45, $90 \mathrm{~cm}$, ABOX 660 & 8227 & $33.0 \pm 0.7$ \\
\hline CG1-A45, $90 \mathrm{~cm}$, ABOX 340 & 8226 & $33.1 \pm 0.8$ \\
\hline $\mathrm{CG} 1-\mathrm{A} 45,90 \mathrm{~cm}, \mathrm{ABOX} 660^{\mathrm{c}}$ & 8222 & $32.8 \pm 0.5$ \\
\hline $\mathrm{CG} 1-\mathrm{A} 45,90 \mathrm{~cm}, \mathrm{ABOX} 880^{\mathrm{c}}$ & 7626 & $33.6 \pm 0.5$ \\
\hline CG1-A48, $96 \mathrm{~cm}$, ABOX 340 & 7615 & $39.8 \pm 0.6$ \\
\hline CG1-A48, $96 \mathrm{~cm}$, ABOX 660 & 7616 & $40.6 \pm 0.8$ \\
\hline CG1-A48, $96 \mathrm{~cm}$, ABOX 880 & 7617 & $40.3 \pm 0.8$ \\
\hline \multicolumn{3}{|l|}{ Riwi } \\
\hline Riwi 13, $65 \mathrm{~cm}$, ABOX 920 & 13005 & $41.3 \pm 1.0$ \\
\hline Riwi 16, $95 \mathrm{~cm}$, ABOX 920 & 13006 & $40.7 \pm 1.3$ \\
\hline \multicolumn{3}{|l|}{ Cuddie Springs } \\
\hline $\mathrm{CS} 1 / 1,1.05-1.15 \mathrm{~m}, \mathrm{ABOX} 880^{\mathrm{b}}$ & 10011 & $28.74 \pm 0.34$ \\
\hline $\mathrm{CS} 1 / 3,1.05-1.15 \mathrm{~m}, \mathrm{ABOX} 920^{\mathrm{c}}$ & 13012 & $28.59 \pm 0.48$ \\
\hline $\mathrm{CS} 3 / 1,1.15-1.35 \mathrm{~m}, \mathrm{ABOX} 880$ & 10319 & $32.00 \pm 0.55$ \\
\hline $\mathrm{CS} 2 / 1,1.35-1.55 \mathrm{~m}, \mathrm{ABOX} 880^{\mathrm{b}}$ & 10012 & $28.78 \pm 0.35$ \\
\hline $\mathrm{CS} 2 / 2,1.35-1.55 \mathrm{~m}, \mathrm{ABOX} 880^{\mathrm{c}}$ & 12309 & $31.34 \pm 1.00$ \\
\hline
\end{tabular}




\section{The Carpenter's Gap Site: Reliable Confirmation of Previous Radiocarbon Ages at $\sim 40$ ka BP}

Carpenter's Gap is a rock shelter site in northwestern West Australia. The sequence is $1 \mathrm{~m}$ deep, and artifacts are found down to the bedrock base (O'Connor 1995). Earlier ${ }^{14} \mathrm{C}$ dating indicated ages of $\sim 40 \mathrm{ka}$ at the base of the sequence (McConnell and O'Connor 2000). In contrast to the Nauwalabila site, there is abundant charcoal all the way down the sequence, and its state of preservation is remarkable.

Multiple samples of charcoal from three levels near the base of the sequence have been ABOX-SC treated and measured by AMS. The results are presented in Table 2 above. Clearly, the ages for a given level are all consistent, both internally and with earlier ${ }^{14} \mathrm{C}$ measurements, and establish beyond reasonable doubt that this site was first occupied by humans $40,000{ }^{14} \mathrm{C}$ years ago. Even the low-temperature fractions of the stepped combustion procedure yield an age similar to the high-temperature fractions, indicating that residual contamination after the chemical pretreatment is minimal. The message from this site is that if one starts with good charcoal, then the dates are likely to be reliable, even at $40 \mathrm{ka} \mathrm{BP}$.

Selected samples from two other sites that had earlier been ${ }^{14} \mathrm{C}$ dated to $~ 30 \mathrm{ka}$ or more using conventional pretreatments and combustion procedures were also subjected to the full $\mathrm{ABOX}-\mathrm{SC}$ procedure and ${ }^{14} \mathrm{C}$ dated by AMS in the course of this work in order to determine whether or not they might be significantly older. Their locations are shown in Figure 3 and the results are presented in Table 2. Riwi is a limestone cave in the southern Kimberleys with a 1-m-deep sequence of human occupation. Details may be found in Balme (2000). Of the two samples, Riwi 13 is from a hearth at a depth of 65 $\mathrm{cm}$, and its age is very similar to that at the base of the sequence at Carpenter's Gap, which is $200 \mathrm{~km}$ to the northwest. It provides additional evidence that humans were active in the Kimberley region of northwest Australia by at least $40 \mathrm{ka}$ BP. Riwi 16 is an isolated charcoal fragment that was picked from near the base of the sequence; its age would suggest that it may be out of sequence, as discussed by Balme (2000). Cuddie Springs is an ephemeral lake site on the other side of the continent in north central NSW. It is of considerable interest because human artefacts and bones of extinct megafauna are found in the same archaeological layers, suggesting strongly that humans and megafauna coexisted at this site (Field and Dodson 1999). Previous AMS ${ }^{14} \mathrm{C}$ dating of charcoal from these layers, using conventional ABA pretreatment, ranged from 28.8 to $33.7 \mathrm{ka} \mathrm{BP}$, and the results obtained here confirm these earlier results.

Figure 3 Location map of the various Australian archaeological sites discussed in the present work

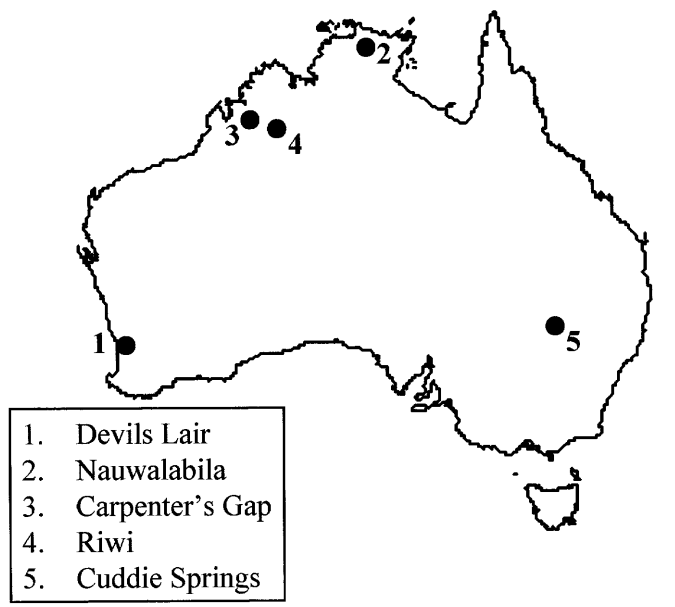




\section{CONCLUSIONS}

Charcoal samples from ancient human occupation sites in Australia have been subjected to a rigorous pretreatment and stepped combustion regime in order to explore the possibility that these sites may be older than earlier ${ }^{14} \mathrm{C}$ dating had suggested. In one case, the Devil's Lair site in southwest Australia, the ABOX-SC methodology has clearly removed vestiges of contamination by more modern carbon and has led to a revised ${ }^{14} \mathrm{C}$ chronology which provides evidence for human occupation of southwest Australia by at least $45 \mathrm{ka} \mathrm{BP}$, and probably 46-47 ka. In marked contrast, the charcoal from depths below $1.3 \mathrm{~m}$ at the Nauwalabila site has been found to have been so severely altered during an episode when the water table was high that not even the ABOX-SC methodology can recover the original carbon. Finally, where the charcoal is well preserved, such as at the Carpenter's Gap site, the ABOX-SC results provide reassurance that earlier ${ }^{14} \mathrm{C}$ results of $\sim 40 \mathrm{ka} \mathrm{BP}$ are indeed true ages and are not simply at the limit of the radiocarbon technique.

\section{ACKNOWLEDGMENTS}

We wish to thank R Jones (Nauwalabila), S O'Connor (Carpenter's Gap), J Field (Cuddie Springs), and $\mathrm{J}$ Balme (Riwi) for providing the charcoal samples analyzed in this study. This work was supported in part by a grant from the Aboriginal and Torres Strait Islanders' Commission.

\section{REFERENCES}

Allen J, Holdaway S. 1995. The contamination of Pleistocene radiocarbon determinations in Australia. Antiquity 69:101-12.

Balme J. 2001. Excavations revealing 40,000 years of occupation at Mimbi Caves in south central Kimberley of Western Australia. Australian Archaeology 50:1-5.

Bird MI, Ayliffe LK, Fifield LK, Turney CSM, Cresswell RG, Barrows TT, David B. 1999. Radiocarbon dating of "old" charcoal using a wet oxidation-stepped combustion procedure. Radiocarbon 41(1):127-40.

Dortch C. 1979a. Devil's Lair, an example of prolonged cave use in south-western Australia. World Archaeology 10:258-79.

Dortch C. 1979b. 33,000 year old stone and bone artefacts from Devil's Lair, Western Australia. Records of the Western Australian Museum 7:329-67.

Dortch CE, Dortch J. 1996. Review of Devil's Lair artefact classification and radiocarbon chronology. Australian Archaeology 43:28-32.

Field J, Dodson J. 1999. Late Pleistocene megafauna and archaeology from Cuddie Springs, southeastern Australia. Proc. of the Prehistoric Society 65:275-301.

Kitagawa H, van der Plicht J. 1998. Atmospheric radiocarbon calibration to 45,000 yr B.P.: Late Glacial fluctuations and cosmogenic isotope production. Science 279:1187-90.

McConnell K, O’Connor S. 1999. Carpenter's Gap Shelter 1: a case for total recovery. In: Mountain MJ, Bow- dery D, editors. Taphonomy: the analysis of processes from phytoliths to megafauna. Research papares in archaeology and natural history. Australian Natural University Publications 30: 23-34.

O'Connell JF, Allen J. 1998. When did humans first arrive in Greater Australia and why is it important to know? Evolutionary Anthropology 6:132-46.

O'Connor S. 1995. Carpenter's Gap Rockshelter 1: 40,000 years of Aboriginal occupation in the Napier Ranges, Kimberley, WA. Australian Archaeology 40: 58-59.

Roberts RG, Jones R, Smith MA 1990. Thermoluminescence dating of a 50,000-year-old human occupation site in northern Australia. Nature 345:153-6.

Roberts RG, Jones R, Spooner NA, Head MJ, Murray AS, Smith MA. 1994. The human colonisation of Australia: optical dates of 53,000 and 60,000 years bracket human arrival at Deaf Adder Gorge, Northern Territory. Quaternary Science Reviews 13:573-84.

Turney CSM, et al. 2001. Early human occupation at Devil's Lair, southwestern Australia. Quaternary Research 55:8-13.

Voelker AHL, Sarnthein M, Grootes PM, Erlenkeuser H, Laj C, Mazaud A, Nadeau M-J, Schleicher M. 1998. Correlation of marine ${ }^{14} \mathrm{C}$ ages from the Nordic Seas with the GISP2 isotope record: implications from ${ }^{14} \mathrm{C}$ calibration beyond 25 ka BP. Radiocarbon 40(2):51734. 